\title{
Uso de Ambiente Virtual de Aprendizagem de Temas Transversais no Ensino de Ciências
}

\author{
Using a Virtual Learning System in \\ transversal themes in Science Teaching
}

Leandro Duso

\begin{abstract}
Resumo
Neste artigo, apresento o relato da utilização de ambientes virtuais de aprendizagem (AVA) como ferramenta auxiliar nas aulas de Biologia com estudantes da segunda série do ensino médio, em uma escola da rede privada. A metodologia constou de ambientes virtuais de aprendizagem como ferramenta para a mediação do processo de ensino e aprendizagem, utilizando atividades elaboradas sobre temas para os quais não se dispunha de tempo para discutir em sala de aula como o da gripe aviária, dos transgênicos e da clonagem. Os resultados mostraram que o uso de ambientes virtuais como ferramenta de aprendizagem possibilita a sistematização de forma diferenciada do conteúdo, levando os educandos a uma aprendizagem mais significativa, promovendo uma maior socialização desses e um maior engajamento nas atividades elaboradas por eles.

Palavras-chave: Ensino de Biologia, Ambientes Virtuais de Aprendizagem, Informática na Educação.

Abstract

In this paper, I present a report about the use of virtual learning environment as an auxiliary tool in Biology classes with students in the high school at in private school. The methodology used virtual learning environments as tool for education process mediation, using elaborated activities about subjects that, wasn't discussed about in classroom due to lack of time, such as the Bird Flue avian influenza, the genetically modified products and the cloning subjects. The results had shown that use of the virtual environment as a learning tool, the differentiated form of content systematization, leading students to a more significant learning, promoting more socialization and enrollment in the activities elaborated for them.
\end{abstract}

Keywords: Teaching of Biology, Virtual learning environment. 


\section{Introdução}

A partir da década de 90, verificou-se no Brasil a grande explosão do uso da Internet, bem como a participação cada vez mais intensa de microcomputadores no ambiente educacional. A rede mundial de computadores, os PCN's e os softwares educacionais, combinados entre si, oferecem novas abordagens ao processo de ensino e aprendizagem, proporcionando inúmeras possibilidades aos professores para buscar novos métodos de ensinar, às escolas para se modernizar e romper velhas estruturas com seus paradigmas já enraizados e aos estudantes para desenvolver melhor as suas potencialidades. Pois segundo LITWIN, (1993, p.5) “A Tecnologia Educacional, assim como a Didática, preocupa-se com as práticas de ensino.".

Sendo assim a tecnologia educacional passou a ser concebida como um "[...] corpo de conhecimentos que, baseando-se em disciplinas cientificas encaminhadas para as práticas do ensino [...]", (Litwin, 1993, p.5). Nesta perspectiva, a tecnologia educacional cumpre o papel de considerar as diversas áreas de conhecimento, no entanto, ainda está fortemente arraigada na idéia de incorporar meios existentes às práticas de ensino. Isto tem contribuído para que os conceitos educacionais não configurem como elementos base no desenvolvimento das ferramentas.

Desta forma, propomos que a tecnologia educacional seja vista como um corpo de conhecimentos que tendo por base conhecimentos das diversas áreas, inclusive da educação, desenvolve e estuda tanto os meios, como sua incorporação na prática pedagógica. Conseqüentemente, as tecnologias educacionais deixam de ter o status de ferramentas na educação, e passam também a configurar como objetos de pesquisas educacionais.

Porém, sabe-se que a incorporação destas tecnologias no âmbito educacional e um desafio para as escolas e professores. Estudos realizados, tendo como objetivo analisar as dificuldades para a incorporação das TIC (PROFORTIC, 2005; Bo y Sáez, 2005; Fuentes et al., 2005; BECTA, 2004), apontam como obstáculos: a escassez de recursos, a falta de formação dos professores, a falta de material e modelos curriculares e a falta de tempo e motivação.

Segundo Perrenoud (2001), a escola não pode ignorar o que ocorre no mundo, pois as novas tecnologias na educação e na comunicação transformam, consideravelmente, não só nossas maneiras de nos comunicar, mas de trabalhar, de decidir, de pensar.

A escola e o professor não podem mais concorrer com a velocidade pelas quais as informações são atualizadas. O simples repasse de informação não sustentará a profissão, se a ele for reduzida. Entretanto, a profissão não se define mais pela transmissão, mas pela reconstrução do conhecimento, permitindo que o aprendente busque suas próprias sustentações argumentativas e não apenas opinião já formada. 
Partindo dessa mudança de paradigma, hoje se faz necessário inventar novos métodos educacionais, que não sejam baseados apenas na transmissão do conhecimento, mas que correspondam e atendam à sociedade aprendente, que assuma esse novo desafio de construção do conhecimento.

Para Demo (2005), cabe ao professor do futuro trabalhar os meios eletrônicos como suporte à aprendizagem, empregando as novas tecnologias nas suas atividades didáticas. A utilização de ambientes virtuais de aprendizagem, se empregados de maneira correta, poderão auxiliar o professor nessa nova modalidade de ensinar, permitindo que o aprendente assuma seu papel de aprender e busque reconstruir seu conhecimento.

O estudo da inovação tecnológica aplicável à educação tem contribuído sobremaneira para entender melhor como acontece a aprendizagem humana. Hoje temos a informática, cuja aplicação em educação já é notória, inevitável e imprescindível, como a Internet, o computador e softwares (DUSO, 2008).

Partindo desse pressuposto, este trabalho tem como objetivo relatar uma experiência na qual foi utilizado Ambientes Virtuais de Aprendizagem (AVA), como suporte a disciplina de Biologia, permitindo uma maior interação entre estudante-professor, utilizando temáticas pautadas na Educação Cientifica e das abordagens visando à inter-relação de Ciência, Tecnologia e Sociedade (CTS), para uma melhor compreensão do mundo em que vivemos.

\section{A Tecnologia na Educação e a Postura do Professor}

Independente da modalidade de ensino, o que parece nítido e evidente é que o mundo contemporâneo já não comporta mais a idéia de que o professor é o dono do conhecimento e que repassa aos estudantes por meio de aula expositivas parte do seu saber, cabendo a esses, tão somente colher e acumular informações. Portanto, novas atitudes e posturas tanto dos professores quanto dos estudantes visam a dar condições de tanto um quanto o outro consigam se adaptar às exigências de um mundo que cada vez mais tem utilizado as novas tecnologias. $O$ cenário atual requer a ruptura da segmentação e do fracionamento para a busca de um ensino mais contextualizado e, por conseguinte, mais adequado às exigências do mundo do trabalho.

Em relação à Educação, segundo Crespo (2002), as transformações que necessitam ser realizadas consistem em passarmos de uma cultura de ensino centrada numa concepção empirista, para uma cultura de aprendizagem, centrada numa concepção interacionista, impulsionando o desenvolvimento da sociedade em rede.

Na cultura de rede, o foco educacional está na interação, na construção do conhecimento, no desenvolvimento de habilidades e competências, na aprendizagem. Respeita-se o ritmo de 
desenvolvimento do estudante, pois se acredita que a aprendizagem é um processo que parte do individual para o coletivo.

Neste contexto de transformações, observa-se, ainda, por parte de muitos professores, um perfil muito conservador e uma forte resistência ao novo. Segundo Perrenoud (2000), isso é proveniente de uma série de fatores, dentre os quais o fato de que a maioria dos profissionais de educação foi formada sob uma perspectiva individualista e auto-suficiente.

Demo (2005, p.5) escreve que "um dos traços mais fortes da globalização é a intensividade do conhecimento. O que mais facilmente se globaliza é a tecnologia". Por outro lado, segundo Perrenoud (2000, p. 19) "é forte a inércia nas estruturas, nos textos e, sobretudo, nas mentes, para que uma nova idéia possa se impor rapidamente".

Na cultura de rede, conforme Primo \& Cassol, (1999), o professor se torna mediador, assumindo papel de problematizador, articulador e orientador da aprendizagem, de forma que $o$ conteúdo seja construído, incentiva as atividades no estudante, o desenvolvimento da autonomia, num processo de interação mútua, ou seja, é construído por meio de negociações realizadas pelos interagentes, aqui entendida como relação estudante-estudante e estudante-professor.

Diante de toda a complexidade desse cenário tecnologicamente avançado, os professores precisam empreender esforços para não só se inteirarem das formas de uso dessas ferramentas tecnológicas, mas também para identificar, nas potencialidades desses recursos, quais as implicações acarretadas à sua postura profissional, ao seu trabalho docente e ao seu papel como educadores. Nesse sentido, Moran (1998) afirma que a Internet é uma ferramenta para professores inquietos, atentos a novidades, que desejam atualizar-se e comunicar-se mais.

Por essa razão é que se concebe que o uso das tecnologias da informação e da comunicação na educação representa um ato bidirecional, pois, ao mesmo tempo que volta-se para a frente, ao utilizar vantagens só disponíveis por meio do avanço da tecnologia, é também, algo que nos induz a olhar para trás, no sentido de se rever conceitos, de se verificar os resultados e, porque não, de aprender um pouco mais, pois como alerta Lévy (1996) “o virtual não se opõe ao real, mas sim ao atual."

A utilização dos Ambientes Virtuais de Aprendizagem (AVA's), softwares desenvolvidos para o gerenciamento da aprendizagem via Web, deve ser um grande canal para que os professores testem, façam experimentos, criem sempre no sentido de melhorar o processo ensino-aprendizagem (MORAN, 1998).

Numa perspectiva construtivista, em que o conhecimento não é repassado, mas sim construído a partir das experiências individuais de cada estudante, o professor-mediador é o que faz a diferença e garante a qualidade da atividade proposta a distância. É ele quem motiva e ativa 
a criação de oportunidades para que sua turma realize seus objetivos e tenha uma experiência produtiva. Para Belloni (1999), o papel do professor é de orientador nos estudos da disciplina pela qual é responsável, deve esclarecer dúvidas e explicar questões relativas aos conteúdos. O professor deve, ainda, fazer com que os estudantes busquem uma resposta e que não esperem uma já pronta, pois é essa a situação que eles vão encontrar na vida e no trabalho.

\section{O Ambiente Virtual de Aprendizagem na Educação}

As tecnologias da informação e da comunicação permitem hoje, por meio de vários recursos, a realização de cursos on line eficazes e de ótima qualidade. Dentre as principais vantagens da tecnologia, está a ampliação das fontes de consulta, pois a Internet fornece diversos meios de acesso a materiais educacionais. Considerando que até bem pouco tempo, os professores e os livros eram as únicas fontes para obtenção das informações necessárias para os estudos escolares ou profissionais, sem dúvida, a Internet traz grandes vantagens. Cabe ao professor procurar formas de otimizar e de aproveitar esses recursos à sua prática pedagógica, incorporando-os de tal forma que se constituam, enfim, parte de seu perfil profissional. Assinalase que nos sistemas de formação a distância não se prescinde do professor, ao contrário, ele passa a ser imprescindível, o elemento-chave para o sucesso da aprendizagem.

A flexibilidade de horários, de local e de ritmo de aprendizado propiciado pelas atividades organizadas no AVA pode contribuir para a percepção de que o conhecimento está disponível e não depende do lugar ou do momento. Além disso, a autonomia de aprendizagem, que surge em decorrência desse processo, leva o professor a rever alguns antigos conceitos. A autonomia, nesse contexto, refere-se à capacidade de o estudante de se antecipar aos comandos dos professores e agregar voluntariamente várias tarefas, intensificando, assim, seu próprio ritmo de trabalho.

Segundo GITIRANA, et. al. (2006), atualmente, observa-se o crescente desenvolvimento de pesquisas em ambientes virtuais que objetivam dar suporte ao ensino. Plataformas como VirtusClass, Aula Net, Black-Board, Moodle vêm surgindo com tal intuito e disponibilizando diversas ferramentas que buscam facilitar o trabalho docente a distância.

O ambiente virtual de aprendizagem por ser um ambiente conveniente, flexível e sem horários pré-definidos, permite que os estudantes possam optar em fazer ou adiar determinada atividade para outro momento. Tal fato traz a necessidade de o professor e o estudante organizarem-se, no sentido de não se perderem ambos no processo de construção de aprendizagem.

A educação a distância mediada por computador, permite, ainda, que o estudante seja realmente ativo, responsável pela sua aprendizagem e, principalmente, aprenda a aprender. No 
entanto, como o discípulo também tem uma cultura de espera por comandos e orientações, cabe ao professor reverter esse quadro, mostrando aos alunos a necessidade de busca pela informação.

Diante de tão vasta gama de possibilidades e características disponíveis num ambiente virtual fica nítida a necessidade de uma atuação mais efetiva do professor e uma atenção mais próxima ao desenvolvimento da atividade planejada e proposta para os jovens.

Ao professor e ao estudante, num ambiente virtual de aprendizagem, cabe o compromisso de suprir as desvantagens ou limitações que a modalidade de ensino a distância pode trazer, como a ausência do contato face a face e se faz necessário o contato constante com o computador.

Além do mais, o professor deve atuar como orientador no processo de aprendizagem já que os jovens podem desenvolver trabalhos em grupo, trocar idéias com os colegas e participar de fóruns de debates. Os debates são importantes, pois preconizam o trabalho em equipe, que é uma característica primordial requerida pelo mercado de trabalho no momento atual.

Outro ponto que merece atenção do professor e requer uma disciplina rígida é a resposta aos questionamentos dos estudantes. Uma atividade intermediada pelos AVA's não permite falhas de comunicação. Se as mensagens não chegam, ou o retorno de resposta é demorado, tais eventos podem desqualificar a qualidade da atividade por parte dos estudantes.

Com base nessas concepções, verifica-se a necessidade de uma atenção mais individualizada do professor em relação aos seus estudantes. Numa atividade mediada por AVA's, isso é imprescindível para a garantia de qualidade da aprendizagem.

\section{Escolha das Mídias}

São muitas as mídias que podem ser utilizadas em atividades educativas. Assim como cada modalidade de ensino requer o tratamento diferenciado do mesmo conteúdo como estar de acordo com os estudantes, quais os objetivos a serem alcançados, qual o espaço e tempo disponíveis para a sua realização em cada um dos suportes mediáticos devemos ter cuidados e formas de tratamento específico que, ao serem utilizados, podem alterar a forma de como se efetiva e como se faz educação.

O planejamento de atividades de ensino que envolve o uso de suportes mediáticos impressos, é diferente, por exemplo, do uso de vídeos e das mídias digitais mais avançados como Internet. Cada tipo de mídia requer um planejamento cuidadoso que vai além da disponibilidade dos equipamentos e da definição de seu uso em determinada aula, ou não. 
$\mathrm{Na}$ parte organizacional, é preciso ter cuidado especial na seleção das atividades, conteúdos e do programa da disciplina que serão veiculados em determinado tipo de mídia. A abordagem de cada assunto requer tratamento diferenciado de acordo com a mídia em que vai ser veiculada. Por outro lado, esses conhecimentos precisam estar comprometidos com o perfil dos estudantes e com os objetivos previstos. É preciso refletir se eles servirão apenas para a aquisição e/ou reprodução dos conhecimentos e habilidades ou se oferecerão condições para a produção de novos conhecimentos e o posicionamento crítico dos estudantes.

Para a utilização do AVA, foram selecionados temas transversais. Segundo Yus (1998), temas transversais são conjuntos de conteúdos e eixos condutores da atividade escolar que, podem ser considerados comuns para várias disciplinas. Yus (1998), também, entende que o objetivo fundamental dos eixos transversais é o das atitudes e das pautas de comportamento; por isso os estudantes deveriam aprender a utilizar estratégias relacionadas com a resolução de problemas abertos e com o desenvolvimento da capacidade de argumentar. Cita, ainda, que os temas transversais surgiram das necessidades de levar para o campo da educação algumas das discussões destinadas a diminuir os problemas que, sob determinados aspectos, são de preocupação comum, como as ambientais, as biotecnológicas, as bioéticas, entre outras.

Compreendo que as proposições anteriores podem ser encontradas na idéia de temas geradores, que foi desenvolvida e utilizada pela pedagogia freiriana. Nessa pedagogia, o tema gerador é entendido como o assunto que centraliza o processo de ensino-aprendizagem, por meio do qual acontecem os estudos, pesquisas, análises, reflexões, discussões e conclusões. Além disso, o processo de escolha dos assuntos, problemas ou temas geradores é fruto de uma mediação entre as responsabilidades dos professores e os interesses dos estudantes.

Os temas geradores propõem-se superar o problema da elaboração dos conteúdos curriculares e da aprendizagem de conceitos disciplinares. Espera-se, por parte dos professores, que busquem estimular seus estudantes a perguntar e provocá-los à reflexão crítica sobre suas próprias perguntas, rompendo com a passividade deles em face às explicações discursivas apenas do professor. Além do mais, "todo o ensino de conteúdos demanda de quem se acha na posição de aprendiz que, a partir de certo momento, vá assumindo a autoria também do conhecimento do objeto em estudo" Freire (1996, p.140).

Conforme Yus (1998), as estratégias de temáticas transversais estão relacionadas à pedagogia crítica e de resistência. Ele compreende que, por meio dessas temáticas, é possível abordar o sentido social do ensino, promovendo, dessa maneira, para que os indivíduos sejam autônomos, críticos e solidários, respeitosos consigo mesmo, com os demais e com o próprio meio. Ou seja, ele sugere que a utilização dessas estratégias contribui "para a criação de uma sociedade mais justa, igualitária e solidária ou que, ao menos, contrabalance os efeitos 
perniciosos que provoca o desenvolvimento em sociedades neoliberais como a nossa" Yus (1998, p.29).

Para este tipo de abordagem, outro aspecto a ser levado em consideração, diz respeito à interação entre os participantes. Os AVA's podem ser utilizados para a realização de atividades isoladas dos estudantes ou atividades com maior interação, com trocas de mensagens entre todos e a realização de projetos integradores e cooperativos.

As atividades comunicativas entre os estudantes virtuais requerem a gestão dos conhecimentos que circulam a orientação e o suporte das discussões estabelecidas, o fortalecimento de processos participativos entre professores e estudantes envolvidos. Além disso, é preciso não apenas gerenciar as pessoas e as tecnologias em uso, mas também as informações que transitam entre os participantes para que a atividade oferecida não se afaste demais de seus objetivos.

As principais mudanças nos processos de interação e comunicação em educação a distância ocorreram com o uso mais intensivo da Internet e nos ambientes virtuais de aprendizagem. As possibilidades de atividades síncronas (Chat's e fóruns) e assíncronas (e-mail) da Internet viabilizam o contato entre pessoas situadas nos mais diferentes espaços, a qualquer hora. A Internet viabiliza também a oferta e o acesso a conteúdos que estejam localizados em sites em qualquer parte do mundo. $\mathrm{O}$ uso de ferramentas comunicativas disponíveis na Internet como o correio eletrônico, chats e fóruns de discussões garantiram a possibilidade de maior troca e diálogo entre professores e estudantes. Articuladas com as mais novas possibilidades tecnológicas como a inserção de vídeos, a comunicação via voz, a visualização dos participantes em tempo real, as mídias digitais caminham para a integração de suas possibilidades oferecendo recursos que viabilizam o oferecimento de educação de qualidade para qualquer pessoa, em qualquer tempo e em qualquer lugar.

Nos ambientes virtuais de aprendizagem, os estudantes acessam diretamente textos, desenhos, fotos, animações, sons e vídeos, na própria página do curso na Internet. Eles podem salvar os arquivos disponíveis ou imprimi-los. Podem também interagir com os professores e com os colegas em chats e fóruns de discussões. Testes, exercícios e demais atividades individuais ou em grupos são possíveis de serem executados e enviados imediatamente para o professor ou para todos os participantes. Os estudantes podem comentar as atividades e contribuir com os seus colegas criando um clima de trocas intelectuais em que todos cooperam para a aprendizagem dos demais. 


\section{Experiência em Ambientes Virtuais de Aprendizagem}

Como professor de ensino médio, tenho buscado novas metodologias para atender as necessidades dos estudantes frente aos desafios da nova sociedade de informação. A reflexão sobre temas polêmicos atuais, na área da Biologia como células-tronco, transgênicos, clonagem, engenharia genética, racismo, entre outros estão permeando a sociedade, principalmente, no que se refere à bioética.

Como o currículo escolar apresenta-se de forma linear, os professores têm de cumprir uma série de listas de conteúdos e não sobra tempo em aula para a reflexão sobre esses temas, como eles senti-me de mãos atadas em não poder promover debates aprofundados em sala de aula.

Tendo essa preocupação tentei buscar saídas para resolver esse dilema. Para tanto, participei de um no congresso de Ensino de Biologia na UFRJ, realizei um minicurso sobre Tecnologias da Informação e Comunicação Aplicadas, e por meio de relatos de colegas, obtive a informação sobre o Virtuaclass, salas virtuais de aprendizagem que poderiam ser estruturadas como apoio a atividades escolares. Essa ferramenta estava disponibilizada no Portal da Universia, (www.universia.com.br/salasvirtuais) e qualquer pessoa interessada poderia montar sua sala virtual, com layout já definidos. A idéia da utilização dessa ferramenta seria para dar suporte às atividades iniciadas em sala de aula, e para as quais não teria tempo para ampliar a discussão.

\section{Ambiente VirtuaClass}

A utilização desse ambiente foi pensada juntamente com os estudantes para discutir temas da atualidade os quais não estão incluídos no currículo disciplinar. Após debate em sala de aula, o tema levantado pelos estudantes foi sobre a Gripe Aviária, que a mídia explorava muito no início do ano de 2006, e que evidenciou o desejo dos alunos de ampliar a discussão para além da sala de aula.

Após estruturação do ambiente virtual, foi necessário um período para a adaptação dos estudantes, esses, no entanto, após duas semanas eles pareciam estar motivados, pois acessavam a ferramenta até duas vezes por dia, para ver se havia alguma novidade. Notei a ansiedade de alguns em sala de aula, questionando-os porque não haviam postado nada durante uma semana. 


\section{Ferramentas utilizadas no VirtusClass}

1. Agenda de atividades: $O$ mediador insere as atividades previstas para serem realizadas pelo grupo de estudo indicando data e hora. Pode ser marcado um encontro no bate-papo, uma leitura disponível na central de documentos para ser discutida em sala de aula, etc.

Essa sessão foi muito importante, pois serviu para planejar as discussões dos temas, tanto do ambiente quanto para as atividades realizadas em aula.

2. Lista de participantes: Espaço onde mediadores e estudantes podem se inscrever e conhecer os demais integrantes do grupo, trocar e-mails e deixar informações a seu respeito.

A principio a estrutura do AVA era para todos os estudantes da segunda série do ensino médio, em torno de aproximadamente 170 estudantes. Ao se cadastrarem como participantes, eles colocavam seu nome e e-mail, alguns, inclusive, colocavam a turma. A dificuldade foi de associar o estudante com a turma em que estava inserido, pois havia um número muito grande de estudantes cadastrados para serem gerenciados.

3. Mural virtual: Espaço para troca de mensagens entre os integrantes do grupo de estudos, permitindo consulta e verificação de mensagens.

O mural funcionou de maneira variada, o professor deixava as mensagens no mural para os estudantes, e eles deixavam mensagem para o professor e aos demais colegas também Algumas vezes, o mural serviu para tirar dúvidas sobre trabalhos, sobre os conteúdos desenvolvidos em sala de aula, etc.

Esse problema poderia ter sido amenizado se houvesse uma sessão para as discussões como fóruns, que se encontram em outros Ambientes Virtuais.

4. Sala de bate-papo: Espaço onde se pode conversar com os outros integrantes do grupo de estudos ou consultar o registro dos bate-papos já ocorridos. Trata-se de uma ferramenta que funciona de forma síncrona, ou seja, o diálogo acontece simultaneamente, como numa conversa, então, todos devem estar acessando essa página ao mesmo tempo.

A sala de bate papo foi pouco utilizada, pois era limitada para apenas 20 participantes e como já dito anteriormente, havia 170 estudantes cadastrados. Mesmo marcando horário para o bate papo, previamente agendado e anotado no mural, houve pouco participação inicial, e os que entravam para discutir o tema proposto, acabavam sanado suas dúvidas sobre a aula presencial.

A comunicação nas salas de bate papos eram todas continuas, não havia possibilidade de saber quem estava conectado à sala, pois só ficava o registro da data e hora da entrada, mas não mostrava a saída do usuário. 
5. Biblioteca de links: Espaço onde estão as referências a Websites (documentos na Web) que tratam do tema de estudo do ambiente, inseridos pelos integrantes do grupo de estudo (mediadores e estudantes). Essa ferramenta também possibilita ao usuário fazer pesquisa na Web a partir de palavras-chaves.

A Biblioteca de links serviu como apoio às referências sobre o tema, como indicador de leituras e buscas. Acabaram se inserindo alguns sites não relacionados com o tema em discussão também, mas que serviram de apoio para as atividades das aulas presenciais.

6. Central de documentos: Espaço para troca de documentos entre mediadores e estudantes do ambiente virtual, permitindo envio e consulta de arquivos dos tipos: página HTML, documento do Bloco de Notas ou do Word, Rich Text Format, apresentação do PowerPoint, planilha do Excel, arquivo Adobe PDF, arquivo compactado WinZip e figura JPeg ou Gif.

A central de documentos também serviu de suporte para a bibliografia indicada para a leitura do tema, não havendo necessidade de deixar material extra em salas de reprografia. Apareceram textos que tratavam de outros assuntos além dos que estavam sendo propostos.

7. Gerenciamento da sala: Só está disponível ao mediador do ambiente. É organizado por acompanhamento dos estudantes e ativar/desativar ambiente.

Permite ao mediador do ambiente virtual acompanhar todas as intervenções, selecionadas por usuário e sessão. Aparece uma tabela com nome do usuário e quantidade de participações ativas. Exibe as intervenções realizadas pelo usuário em cada sessão do ambiente.

O gerenciamento de sala permitiu editar material e controlar as participações no ambiente. A dificuldade maior foi o excessivo número de estudantes que utilizavam esse ambiente e a realização da avaliação individual sob o aspecto da participação efetiva de determinado estudante.

Na metade do ano de 2006, o AVA que estava hospedado no portal Universia foi encerrado, não pude dar continuidade à atividade que estava sendo realizada, em troca foi-me oferecido a ferramenta TeleEduc.

\section{Ambiente TeleEduc}

O TelEduc é um ambiente para realização de cursos a distância por meio da Internet. Desenvolvido no Nied (Núcleo de Informática Aplicada a Educação) sob a orientação da Profa. Dra. Heloísa Vieira da Rocha do Instituto de Computação da Unicamp (Universidade Estadual de Campinas) , a partir de uma metodologia de formação de professores construída com base na análise das várias experiências presenciais realizadas pelos profissionais do núcleo. 
O ambiente é parte integrante da dissertação de mestrado "Formação a Distância de Recursos Humanos para Informática Educativa" de autoria de Alessandra de Dutra e Cerceau.

O Nied, como uma de suas linhas de pesquisa, tem realizado diversos cursos a distância utilizando o TelEduc desde 1998, acompanhando progressivamente o desenvolvimento do ambiente.

Na página de suporte do ambiente virtual TelEduc encontra-se informações gerais sobre o ambiente (http://teleduc.nied.unicamp.br/ teleduc/pagina_inicial/estrutura.php). Suas ferramentas são apresentadas e seus propósitos de utilização são explicitados.

O ambiente possui um esquema de autenticação de acesso aos cursos. Para que formadores, coordenadores, estudantes, convidados e visitantes tenham acesso ao curso é preciso que se tenha uma senha e uma identificação pessoal (login), ambas solicitadas ao participante sempre que ele acessar o curso.

A página de entrada do curso é dividida em duas partes. À esquerda, estão as ferramentas que serão utilizadas durante o curso e, à direita, é apresentado o conteúdo correspondente àquela determinada ferramenta selecionada na parte esquerda. Ao entrar no curso, é apresentado o conteúdo da ferramenta "Agenda" que contém informações atualizadas, dicas ou sugestões dos formadores para os estudantes. Essa página funciona como um canal de comunicação direto entre os formadores e os estudantes. Nela, são colocadas informações que seriam fornecidas normalmente no início de uma aula presencial. O conteúdo de "Agenda" é atualizado de acordo com a dinâmica do curso.

Cada curso apoiado pelo ambiente TelEduc pode utilizar um subconjunto das ferramentas descritas a seguir. Assim, pode acontecer de em um determinado momento do curso algumas ferramentas não estarem visíveis no menu à esquerda e, portanto, não disponíveis. Oferecer ou não uma ferramenta, em diferentes momentos do curso, faz parte da metodologia adotada por cada formador. Geralmente, se há a inserção de uma nova ferramenta, esse fato é avisado ao estudante por meio da Agenda.

\section{Ferramentas utilizadas do TelEduc}

1. Agenda: É a página de entrada do ambiente e do curso em andamento. Traz a programação de um determinado período do curso (diária semanal, etc.).

2. Atividades: Apresenta as atividades a serem realizadas durante o curso.

3. Material de Apoio: Apresenta informações úteis relacionadas à temática do curso, subsidiando o desenvolvimento das atividades propostas. 
4. Leituras: Apresenta artigos relacionados à temática do curso, podendo incluir sugestões de revistas, jornais, endereços na Web, etc.

5. Exercícios: Ferramenta para criação/edição e gerenciamento de Exercícios com questões dissertativas, de múltipla-escolha, de associação de colunas e de verdadeiro ou falso.

6. Mural: Espaço reservado para que todos os participantes possam disponibilizar informações consideradas relevantes para o contexto do curso

7. Fóruns de Discussão: Permite acesso a uma página que contém tópicos que estão em discussão naquele momento do curso. O acompanhamento da discussão se dá por meio da visualização de forma estruturada das mensagens já enviadas e, a participação, por meio do envio de mensagens.

8. Bate-Papo: Permite uma conversa em tempo-real entre os estudantes do curso e os formadores. Os horários de bate-papo com a presença dos formadores são, geralmente, informados na "Agenda". Se houver interesse do grupo de estudantes, o bate-papo pode ser utilizado em outros horários.

9. Perfil: Trata-se de um espaço reservado para que cada participante do curso possa se apresentar aos demais de maneira informal, descrevendo suas principais características, além de permitir a edição de dados pessoais. O objetivo fundamental do Perfil é fornecer um mecanismo para que os participantes possam se "conhecer a distância" visando a ações de comprometimento entre o grupo. Além disso, favorece a escolha de parceiros para o desenvolvimento de atividades do curso (formação de grupos de pessoas com interesses em comum).

10. Diário de Bordo: Como o nome sugere, trata-se de um espaço reservado para que cada possa registrar suas experiências ao longo da participação do curso: sucessos, dificuldades, dúvidas, anseios. Objetiva proporcionar meios que desencadeiem um processo reflexivo a respeito do processo de aprendizagem de cada participante. As anotações pessoais podem ser compartilhadas ou não com os demais. Em caso positivo, podem ser lidas e/ou comentadas pelas outras pessoas, servindo também como um outro meio de comunicação.

11. Portfólio: Nessa ferramenta, os participantes do curso podem armazenar textos e arquivos utilizados e/ou desenvolvidos durante o curso, bem como endereços da Internet. Esses dados podem ser particulares, compartilhados apenas com os formadores ou compartilhados com todos os participantes do curso. Cada participante pode ver os demais portfólios e comentá-los se assim o desejar.

12. Acessos: Permite acompanhar a freqüência de acesso dos usuários ao curso e às suas ferramentas. 


\section{Principais vantagens na utilização dos Ambientes Virtuais de Aprendizagem}

Autonomia do estudante em discutir os temas mesmo sem a presença do professor, permitindo interagir com os colegas embora seja de outra turma. As paredes entre turmas foram "quebradas".

Não há horário especifico para sanar dúvidas. A qualquer hora o estudante poderia relatar sua dúvida e permitir ao professor intervir de maneira eficaz na resolução das dificuldades.

Percebi que houve uma grande participação de estudantes "tímidos", que não participam muito em sala de aula.

Não houve dificuldades de acesso, nem de cadastramento e na navegação da ferramenta.

\section{Problemas observados durante o processo.}

Uma dificuldade encontrada foi a falta de sessão para fóruns de debates, a ferramenta é limitada às interações buscando a utilização do mural ou das salas de bate papos, porém essas foram limitadas e não houve sistematização pelos diferentes questionamentos de temas pelos estudantes.

Organização de horário para o bate papo, e número reduzido de pessoas nas salas de bate papo. Todos os estudantes de uma turma não poderiam estar interagindo simultaneamente no mesmo horário. Porém os participantes interagiram e discutiram o tema, sanando suas dificuldades teóricas. $\mathrm{O}$ diálogo foi bastante produtivo entre os estudantes participantes.

\section{Considerações Finais}

O trabalho relacionado com o ensino-aprendizagem desafia o professor a uma atualização constante, uma maior percepção dos conhecimentos prévios dos estudantes, para redirecionar os conteúdos na via de seus interesses. Como a produção de informações e conhecimentos tem a velocidade muito superior a nossa capacidade de absorção, precisamos estar em constante formação para ampliar os saberes. Reestruturar nossa sistemática de ensino permite que nossos objetivos sejam realmente o de construir o saber, organizar e sistematizar os conhecimentos sociais, científicos e tecnológicos. 
Nesse sentido, o uso do ambiente virtual de aprendizagem auxiliou a dinâmica e a sistematização da discussão dos temas propostos. A atividade realizada na modalidade a distância não apresentou nenhum problema para os desafios da aprendizagem, pelo contrário, durante o processo puderam-se observar as relações ocorridas mediante ferramentas do ambiente para a construção do conhecimento que permitiram perceber diferentes etapas desse processo, evidenciando que a aprendizagem vai se consolidando gradativamente.

Os estudantes demonstram que, no modelo tradicional, o desenvolvimento de conhecimento dificulta a adoção de uma postura mais autônoma na busca do aprender a aprender. Não podemos esquecer que temos uma longa vivência com as aulas presenciais e romper com essa idéia não é fácil, porém, estudar a distância mediada pelos AVA compreende pesquisar, elaborar, ler e também orientar.

Por isso, pode-se perceber que estudantes acostumados com métodos tradicionais de aprendizagem, não conseguiram guiar-se sozinhos nesses ambientes, sendo sempre necessário a presença de um mediador para auxiliar a construção do conhecimento. Isso resultou a dialogicidade e a importância da mediação como aspectos fundamentais no ensinoaprendizagem. A relação de diálogo, estudante-estudante, professor-estudante, foi favorecida por meio dessa ferramenta permitindo romper com a distância existente entre ambos, geralmente, nas classes tradicionais.

A partir do trabalho realizado a distância, observou-se que a utilização de ambiente de virtual de aprendizagem, tornou as aulas mais dinâmicas e interessantes, aumentando a interação entre os estudantes e desses com os professores, buscando melhorar a qualidade do ensino.

O sucesso da aprendizagem nas atividades realizadas com os estudantes de ensino médio por meio de Ambientes Virtuais de Aprendizagem está estreitamente relacionado com a possibilidade de criar condições para que ocorram interações sociais. Essas estão também relacionadas ao contexto pedagógico que sustenta a proposta e aplicação da disciplina. 


\section{Referências}

BECTA (British Educational Communications and Technology Agency). A review of the research literature on barriers to the uptake of ICT by teachers. 2004.

BELLONI, M. L. Professor coletivo: Quem ensina a distância? Educação a Distância. Campinas: Autores Associados, 1999.

BO, R. M.; SÁEZ. A. Dimensiones obtenidas en los obstáculos percibidos para la integración de las nuevas tecnologías de la información y la comunicación (NTIC) por parte de los profesores de la Comunidad Valenciana. Actas del XII Congreso Nacional de Modelos de Investigación Educativa. 2005

CRESPO, S.; SCHELMMER, E. S. AVA: um ambiente virtual baseado em comunidades. In: Simpósio Brasileiro de Informática na Educação (SBIE), 13., 2002, São Leopoldo. Anais. São Leopoldo: Unisinos, 2002.

DEMO, P. Professor do futuro e reconstrução do conhecimento. 3a ed. Petrópolis, RJ. Vozes, 2005.

DUSO, L. Ambientes Virtuais de aprendizagem no ensino de Biologia. In: Borges, R. M. R.; Basso, N. R. S.; Filho, J. B. R. Propostas intertivas na educação científica e tecnológica. Porto Alegre: EDIPUCRS, 2008.

FREIRE, P. Pedagogia da autonomia: saberes necessários à prática educativa. São Paulo: Paz e Terra, 1996.

FUENTES, J. A. E., ORTEGA, J. A. C., LORENZO D. C. Tecnofobia como déficit formativo. Investigando la integración curricular de las TIC en centros públicos de ámbito rural y urbano. Educar, 36 169-180. 2005.

GITIRANA, V.; ABRANCHES, S.P.; BELLEMAIN, F.; CAVALCANTE, P.S.; BELLEMAIN, P.M.B.; LINS, W.C.B. CONCEITOS PEDAGÓGICOS ESQUECIDOS - Uma análise de ambientes de aprendizagem e os fundamentos do Ambiente Didático Virtual. In: XIII ENDIPE - Encontro de Didática e Prática de Ensino, 2006, Recife. Anais do XIII ENDIPE, 2006.

LÉVY, Pierre. O que é virtual? São Paulo: Editora 34, 1996.

LITWIN, E. Presentación. Cuadernos de la Cátedra de Tecnologia Educativa. Buenos Aires: Faculdade de Filosofia e Letras, Oficinas de Publicaciones. 1993.

MORAN, J. M. Internet no ensino universitário: pesquisa e comunicação na sala de aula. InterfaceComunicação, Saúde, Educação, v. 2 n. 3, p.125-131, Ago.1998.

PERRENOUD, P. Dez novas competências para ensinar. Porto Alegre: Artmed, 2000. 
PERRENOUD, P. Agindo na urgência, atuando na incerteza. Porto Alegre: Artmed, 2001.

PRIMO, A. F. T.; CASSOL, M. B. F. Explorando os conceitos de interatividade: definições e taxonomias. Informática na Educação: teoria e prática. Porto Alegre, v.2, n.2, p. 65-80, out 1999.

PROFORTIC. La formación de los profesores en las TIC como dimensión clave del impacto en el proceso de integración: necesidades, currículo y modelos de formación-innovación. Coord. Jesús Suárez. 2005.

YUS, R. Temas transversais em busca de uma nova escola. Porto Alegre: Artmed, 1998.

Leandro Duso: Professor de Biologia do Centro Tecnológico Universidade de Caxias do Sul e mestre em Educação em Ciências e Matemática pela Pontifícia Universidade Católica do Rio Grande do Sul. leandroduso@yahoo.com.br 